\title{
Tau imaging detects distinctive distribution of tau pathology in ALS/PDC on the Kii Peninsula
}

Hitoshi Shinotoh, MD, PhD, Hitoshi Shimada, MD, PhD, Yasumasa Kokubo, MD, PhD, Kenji Tagai, MD, Fumitoshi Niwa, MD, PhD, Soichiro Kitamura, MD, PhD, Hironobu Endo, MD, PhD, Maiko Ono, PhD, Yasuyuki Kimura, MD, PhD, Shigeki Hirano, MD, PhD, Maya Mimuro, MD, PhD, Masanori Ichise, MD, PhD, Naruhiko Sahara, PhD, Ming-Rong Zhang, PhD, Tetsuya Suhara, MD, PhD, and Makoto Higuchi, MD, PhD

Neurology ${ }^{\circledR}$ 2019;92:e136-e147. doi:10.1212/WNL.0000000000006736

\section{Abstract}

\section{Objective}

To characterize the distribution of tau pathology in patients with amyotrophic lateral sclerosis/ parkinsonism dementia complex on the Kii Peninsula (Kii ALS/PDC) by tau PET using $\left[{ }^{11} \mathrm{C}\right]$ PBB3 as ligand.

\section{Methods}

This is a cross-sectional study of 5 patients with ALS/PDC and one asymptomatic participant with a dense family history of ALS/PDC from the Kii Peninsula who took part in this study. All were men, and their age was $76 \pm 8$ (mean $\pm S D)$ years. Thirteen healthy men $(69 \pm 6$ years) participated as healthy controls (HCs). Dynamic PET scans were performed following injection of $\left[{ }^{11} \mathrm{C}\right] \mathrm{PBB} 3$, and parametric $\mathrm{PET}$ images were generated by voxel-by-voxel calculation of binding potential $\left(B P^{*}{ }_{N D}\right)$ using a multilinear reference tissue model. $\left[{ }^{11} \mathrm{C}\right]$ Pittsburgh compound $\mathrm{B}(\mathrm{PiB}) \mathrm{PET}, \mathrm{MRI}$, and cognitive tests were also performed.

\section{Results}

A voxel-based comparison of $\left[{ }^{11} \mathrm{C}\right] \mathrm{PBB} 3 \mathrm{BP}{ }_{\mathrm{ND}}^{*}$ illustrated PET-detectable tau deposition in the cerebral cortex and white matter, and pontine basis including the corticospinal tract in Kii ALS/PDC patients compared with HCs (uncorrected $p<0.05$ ). Group-wise volume of interest analysis of $\left[{ }^{11} \mathrm{C}\right] \mathrm{PBB} 3 B P^{*}$ ND images showed increased $B P^{*}{ }_{\mathrm{ND}}$ in the hippocampus and in frontal and parietal white matters of Kii ALS/PDC patients relative to HCs $(p<0.05$, HolmSidak multiple comparisons test). $B P_{\mathrm{ND}}^{*}$ in frontal, temporal, and parietal gray matters correlated with Mini-Mental State Examination scores in Kii ALS/PDC patients $(p<0.05)$. All Kii ALS/PDC patients were negative for $\left[{ }^{11} \mathrm{C}\right] \mathrm{PiB}$ ( $\beta$-amyloid) except one with marginal positivity.

\section{Conclusion}

$\left[{ }^{11} \mathrm{C}\right]$ PBB3 PET visualized the characteristic topography of tau pathology in Kii ALS/PDC, corresponding to clinical phenotypes of this disease.

\author{
Correspondence \\ Dr. Shinotoh \\ hitoshi.shinoto@nifty.com \\ or Dr. Kokubo \\ ktyktykty@me.com
}

From the Departments of Functional Brain Imaging Research (H. Shinotoh, H. Shimada, K.T., S.K., M.O., Y. Kimura, S.H., M.I., N.S., T.S., M.H.) and Radiopharmaceuticals Development (M.-R.Z.), National Institute of Radiological Sciences, National Institutes for Quantum and Radiological Science and Technology, Chiba; Neurology Clinic Chiba (H. Shinotoh); Kii ALS/ PDC Research Center (Y. Kokubo), Mie University; Department of Neurology and Gerontology (F.N.), Graduate School of Medical Science, Kyoto Prefectural University of Medicine; Department of Psychiatry (S.K.), Nara Medical University; Division of Neurology (H.E.), Kobe University Graduate School of Medicine, Hyogo; Center for Development of Advanced Medicine for Dementia, Department of Neurology (Y. Kimura), National Institute for Geriatrics and Gerontology, Aichi; Department of Neurology (S.H.), Chiba University; and Department of Neuropathology (M.M.), Institute for Medical Science of Aging, Aichi Medical University, Japan.

Go to Neurology.org/N for full disclosures. Funding information and disclosures deemed relevant by the authors, if any, are provided at the end of the article. This study was registered with UMIN Clinical Trials Registry (UMIN 000015453).

The Article Processing Charge was funded by Research and Development Grants for Dementia (16768966) from the Japan Agency for Medical Research and Development (AMED).

This is an open access article distributed under the terms of the Creative Commons Attribution-NonCommercial-NoDerivatives License 4.0 (CC BY-NC-ND), which permits downloading and sharing the work provided it is properly cited. The work cannot be changed in any way or used commercially without permission from the journal. 


\section{Glossary}

$\mathbf{A} \boldsymbol{\beta}=\beta$-amyloid; $\mathbf{A D}=$ Alzheimer disease; ALS = amyotrophic lateral sclerosis; $\left[{ }^{11} \mathbf{C}\right] \mathbf{P B B} 3=2-\left([1 E, 3 E]-4-\left[6-\left(\left[{ }^{11} \mathrm{C}\right]\right.\right.\right.$ methylamino)pyridin-3-yl] buta-1,3-dienyl)benzo[d] thiazol-6-ol; CDR = Clinical Dementia Rating; FAB = Frontal Assessment Battery; HC = healthy control; MAO-B = monoamine oxidase B; MMSE = Mini-Mental State Examination; NFT = neurofibrillary tangle; NPI = Neuropsychological Inventory; PDC = parkinsonism dementia complex; PiB = Pittsburgh compound B; SOB = sum of boxes; SUVR = standardized uptake value ratio; UPDRS = Unified Parkinson's Disease Rating Scale; VOI $=$ volume of interest.

The Kii Peninsula of Japan is a high-incidence foci of amyotrophic lateral sclerosis/parkinsonism dementia complex (ALS/PDC), similar to the island of Guam. ${ }^{1}$ ALS and PDC clinically occur separately or in combination, and most investigators consider ALS and PDC to be different manifestations of a single disease entity. ${ }^{1-3}$ The neuropathologic hallmarks of ALS/PDC of Kii are widespread neurofibrillary tangles (NFTs) and neuropil threads, most predominantly in medial temporal and frontal cortices, and less in other cortices, subcortical nuclei, brainstem, and spinal cord. ${ }^{1-3}$ Taupositive astrocytes were also focally present in white matter. ${ }^{3}$ NFTs in Kii ALS/PDC are ultrastructurally characterized as helical filaments composed of all 6 tau isoforms, similar to those in Alzheimer disease (AD) and Guamanian ALS/ PDC. ${ }^{1,4,5}$ Kii ALS/PDC differs from AD because of different NFT distribution and lack of abundant senile plaque in brain. $^{1-3}$

Genetic and environmental factors are implicated in Kii ALS/ PDC pathogenesis. ${ }^{6}$ The high-incidence foci of ALS/PDC on the Kii Peninsula may provide a clue to the pathogenesis of this and other related neurodegenerative disorders. It would be particularly important to clarify the amount and spatial extent of tau pathology among living Kii patients with ALS/ PDC to identify modifiers of tau fibril formation and dissemination.

We developed 2-([1E,3E]-4-[6-([ $\left.{ }^{11} \mathrm{C}\right]$ methylamino $)$ pyridin3-yl]buta-1,3-dienyl)benzo[ $d]$ thiazol-6-ol $\left(\left[{ }^{11} \mathrm{C}\right] \mathrm{PBB} 3\right)$ as a PET imaging agent for pathologic tau lesions, and have successfully imaged tau aggregates in patients with $\mathrm{AD}$ and a patient with corticobasal syndrome by $\left[{ }^{11} \mathrm{C}\right] \mathrm{PBB} 3 \mathrm{PET} .{ }^{7,8}$ Based on this in vivo imaging technology, the present study aims to characterize the distribution of tau aggregates in relation to clinical phenotypes of Kii ALS/PDC.

\section{Methods}

Five patients with ALS/PDC ${ }^{9}$ and one asymptomatic participant with a dense family history of ALS/PDC from the Kii Peninsula took part in this study. Thirteen healthy men $(69 \pm$ 6 years old) participated as healthy controls (old HCs). All participants underwent neuropsychological assessments, MRI, and PET scans with $\left[{ }^{11} \mathrm{C}\right] \mathrm{PBB} 3$ for tau imaging, and with $\left[{ }^{11} \mathrm{C}\right]$ Pittsburgh compound B (PiB) for $\beta$-amyloid (A $\beta$ ) imaging. Details of the methods are presented in appendix 1 .

\section{Results}

\section{Demographics}

Demographics of Kii ALS/PDC patients and old HCs are summarized in the table. Six Kii ALS/PD patients consisted of 1 asymptomatic participant, 4 ALS/PDC patients, and 1 PDC patient. There was no pure ALS patient. There was no notable age difference between the 6 Kii ALS/PD patients and the 13 old HCs. Years of education of Kii ALS/PDC patients were less than those of old HCs $(p<0.01)$. Kii ALS/PDC patients presented lower Mini-Mental State Examination (MMSE) ${ }^{10}$ and Frontal Assessment Battery (FAB) scores, ${ }^{11}$ and higher Clinical Dementia Rating (CDR) sum of boxes (SOB), ${ }^{12}$ Neuropsychological Inventory (NPI), ${ }^{13}$ and Unified Parkinson's Disease Rating Scale (UPDRS) motor scores, ${ }^{14}$ than old HCs $(p<0.01)$.

\section{PET imaging}

$\left[{ }^{11} \mathrm{C}\right] \mathrm{PBB} 3$ binding was increased in characteristic brain regions of Kii ALS/PDC patients compared with old HCs (figures 1-4). SPM12 (Wellcome Department of Cognitive Neurology, London, UK) analysis of the asymptomatic participant (patient 1 ) vs the 13 old HCs showed regions with increased $\left[{ }^{11} \mathrm{C}\right] \mathrm{PBB} 3$ binding potential $\left(B P_{\mathrm{ND}}^{*}\right)$ in cerebral gray and subcortical white matter and the pontine base of this individual (figure 2). In patient 2, $\left[{ }^{11} \mathrm{C}\right] \mathrm{PBB} 3 \mathrm{BP}{ }_{\mathrm{ND}}^{*}$ was increased in the deep cerebral white matter and brainstem, including the corticospinal tract, ${ }^{15}$ rather than neocortical gray matter areas. Noticeable increases of $\left[{ }^{11} \mathrm{C}\right] \mathrm{PBB} 3 \mathrm{BP}_{\mathrm{ND}}^{*}$ were more extensively observed in cerebral gray and white matter regions, brainstem, and cerebellum of patients 3,5 , and 6 . There was a trend of increased $B P^{*}{ }_{N D}$ in the brain associated with higher CDR SOB, but patient 4 was an outlier with only modest increase of $\left[{ }^{11} \mathrm{C}\right] \mathrm{PBB} 3 \mathrm{BP}{ }_{\mathrm{ND}}^{*}$ in the brain compared with patients 3,5 , and 6 . High $B P^{*}{ }_{N D}$ was additionally seen in the striatum of patients 3 and 6 (figure 2). Group-wise 2-sample $t$ test by SPM demonstrated increased $\left[{ }^{11} \mathrm{C}\right] \mathrm{PBB} 3 \mathrm{BP}{ }_{\mathrm{ND}}^{*}$ in cerebral gray and subcortical white matter, deep white matter including the corticospinal tract, pontine basis, and cerebellum of Kii ALS/PDC patients compared with old HCs (figure 3).

In a group-wise volume of interest (VOI) analysis of $\left[{ }^{11} \mathrm{C}\right]$ PBB3 PET data, $B P^{*}{ }_{N D}$ for this radioligand was higher in the hippocampus and in frontal and parietal white matter of Kii ALS/PDC patients than in old HCs (figure 4). In Kii ALS/PDC patients, MMSE scores were positively correlated with $B P_{\mathrm{ND}}^{*}$ in frontal $\left(r_{\mathrm{s}}=-0.886, p<0.05\right)$, temporal $\left(r_{\mathrm{s}}=-0.943, p<0.05\right)$, 
Table Demographics of Kii ALS/PDC patients and old HCs

\begin{tabular}{|c|c|c|c|c|c|c|c|c|}
\hline & \multicolumn{7}{|c|}{ Kii ALS/PDC } & \multirow[b]{2}{*}{ Old HCs, mean \pm SD } \\
\hline & Patient 1 & Patient 2 & Patient 3 & Patient 4 & Patient 5 & Patient 6 & Mean \pm SD & \\
\hline Age, y/sex & $67 / \mathrm{M}$ & $68 / \mathrm{M}$ & 83/M & 78/M & 85/M & 71/M & $76 \pm 8$ & $69 \pm 6$ \\
\hline Family history of ALS/PDC & Yes & Yes & No & Yes & No & Yes & & \\
\hline Duration of illness, y & - & 8 & 3 & 2 & 6 & 18 & $7.4 \pm 6.4$ & - \\
\hline Upper/lower motor neuron signs & - & $+++/+$ & $-1+$ & +/++ & $-1-$ & $++/+$ & & \\
\hline Parkinsonism & - & + & ++ & ++ & ++ & ++ & & \\
\hline Dementia & - & - & + & + & ++ & +++ & & \\
\hline \multirow[t]{5}{*}{ Neuropsychiatric symptoms } & - & Anxiety & Nighttime behavior disturbances & Apathy & Apathy & Hallucinations & & \\
\hline & & Irritability & & Anxiety & & Apathy & & \\
\hline & & & & Dysphoria & & Aberrant & & \\
\hline & & & & Irritability & & motor & & \\
\hline & & & & Agitation & & behavior & & \\
\hline Education, y & 12 & 12 & 8 & 9 & 6 & 9 & $9.3 \pm 2.3^{\mathrm{a}}$ & $15.6 \pm 1.2$ \\
\hline MMSE & 29 & 28 & 18 & 23 & 24 & 12 & $22.3 \pm 6.4^{a}$ & $28.6 \pm 1.8$ \\
\hline FAB & 18 & 12 & 9 & 13 & 14 & 5 & $11.5 \pm 3.9^{a}$ & $17.1 \pm 0.9$ \\
\hline CDR-SOB & 0 & 1 & 2.5 & 3 & 5 & 15 & $4.4 \pm 5.5^{a}$ & 0 \\
\hline NPI & 0 & 2 & 4 & 16 & 8 & 24 & $9.0 \pm 9.3^{a}$ & 0 \\
\hline UPDRS motor & 0 & 49 & 25 & 32 & 37 & 44 & $31.2 \pm 17.5^{\mathrm{a}}$ & $0.8 \pm 0.5$ \\
\hline PiB SUVR & 1.14 & 1.04 & 1.27 & 1.31 & 1.12 & 1.11 & $1.16 \pm 0.10$ & $1.23 \pm 0.08$ \\
\hline
\end{tabular}

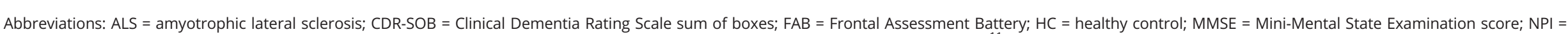

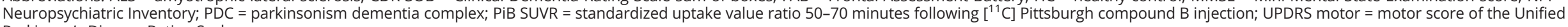
Parkinson's Disease Rating Scale.

Patients are presented in the order of sum of boxes. $1=$ none, $+=$ mild, $++=$ moderate, $+++=$ severe

a $p<0.01$ compared with 13 old HCs. 


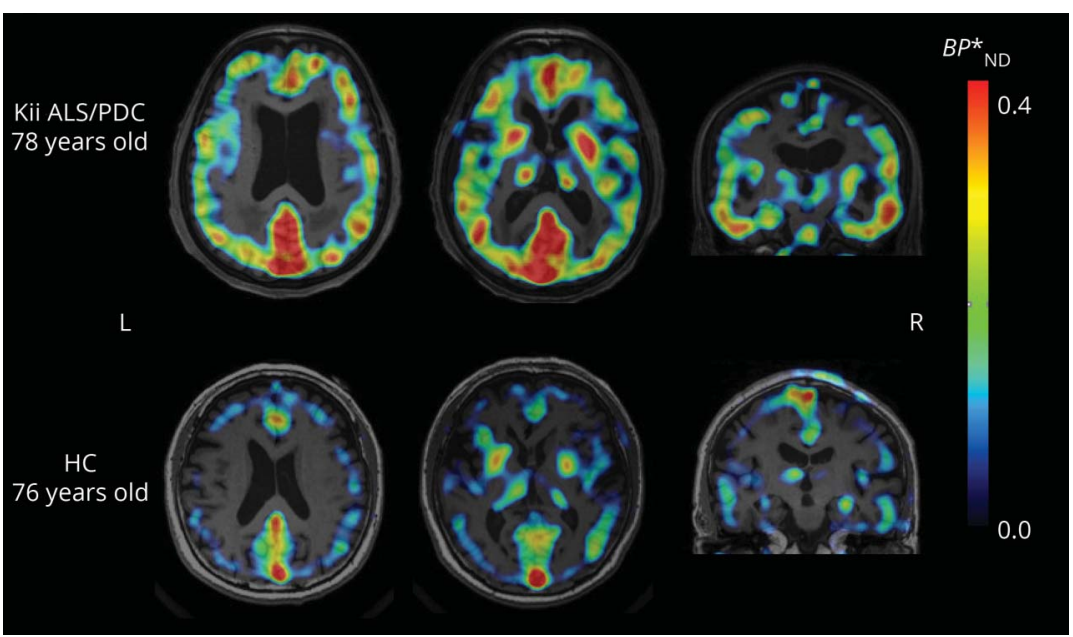

PET images in the upper row are of a 78-year-old Kii amyotrophic lateral sclerosis (ALS)/parkinsonism dementia complex (PDC) patient (case 4) and those in the lower row are of a 76-year-old healthy control $(\mathrm{HC})$. Two trans-axial and one coronal PET image are displayed in the upper and lower rows. Extensive regions with high $B P^{\star}$ ND are seen in the cerebral cortex in the Kii ALS/PDC patient compared with HC. There are voxels with high $B{ }^{*}{ }_{N D}$ in the superior sagittal sinuses of the Kii ALS/PDC patient and the HC, which are thought to be off-target binding to venous sinuses. ${ }^{7}$ $\left[{ }^{11} \mathrm{C}\right] \mathrm{PBB} 3=2-\left([1 E, 3 E]-4-\left[6-\left(\left[{ }^{11} \mathrm{C}\right]\right.\right.\right.$ methylamino $)$ pyridin3-yl]buta-1,3-dienyl)benzo[d]thiazol-6-ol. and parietal gray matter $\left(r_{\mathrm{s}}=0.943, p<0.05\right)$ by Spearman correlational analysis. NPI scores were also correlated with $B P_{\mathrm{ND}}^{*}$ in frontal gray matter $\left(r_{\mathrm{s}}=0.886, p<0.05\right)$. There was no correlation between CDR-SOB, FAB scores, UPDRS motor scores, and $B P^{*} \mathrm{ND}$ in any regions of these patients. $\left[{ }^{11} \mathrm{C}\right] \mathrm{PiB}$ PET images were negative in the $6 \mathrm{Kii}$ ALS/PDC patients except for patient 4, who showed marginal positivity. All HCs were PiB-negative, and there was no difference in $\left[{ }^{11} \mathrm{C}\right] \mathrm{PiB}$ between Kii ALS/PDC patients and old HCs (table).

Figure 2 Increase of $\left[{ }^{11} \mathrm{C}\right] \mathrm{PBB} 3$ binding potential $\left(B P^{*}{ }_{N D}\right)$ in each of the Kii amyotrophic lateral sclerosis/parkinsonism dementia complex patients compared with old healthy controls

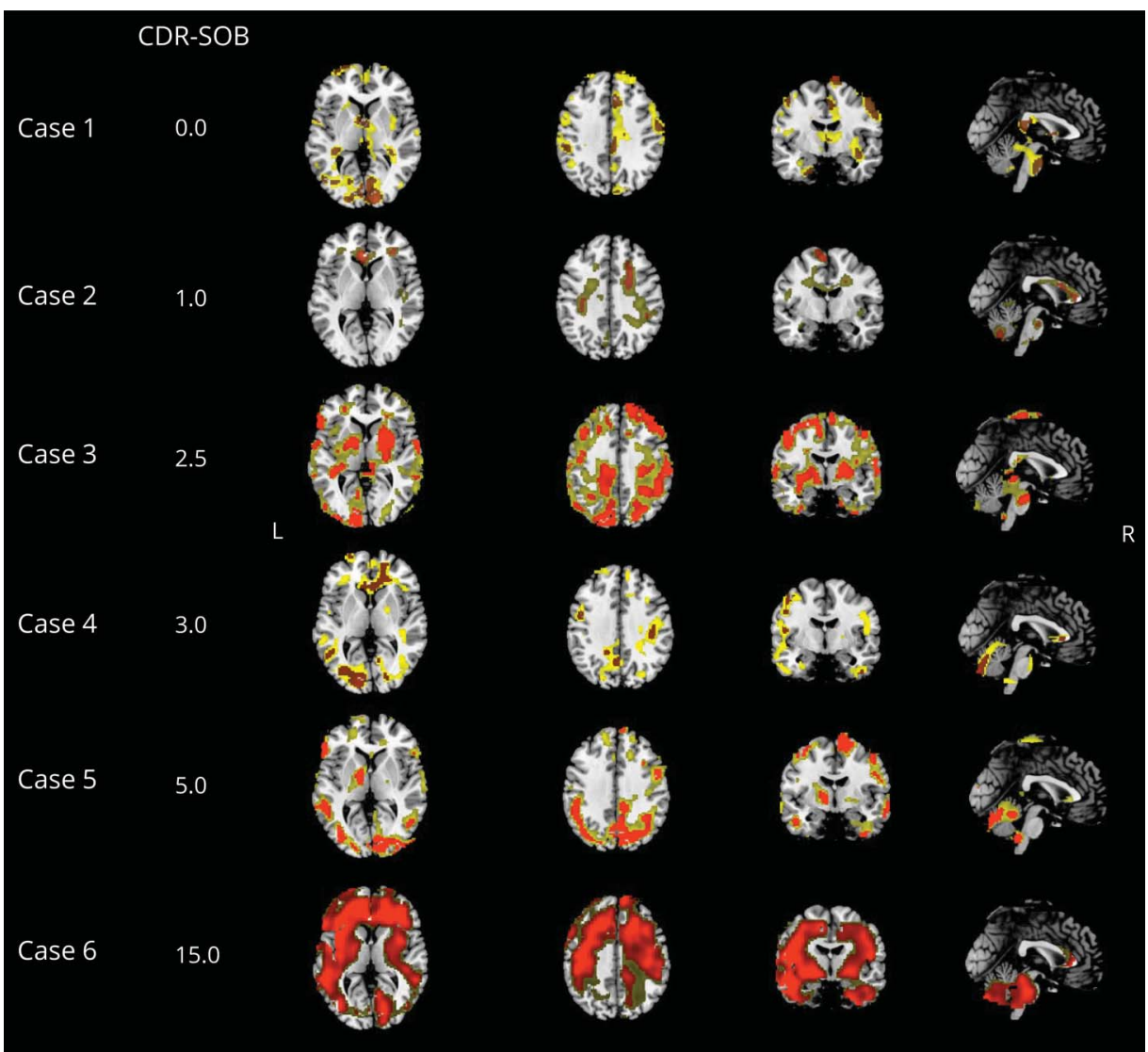

Two axial images $(z=76,108)$, a coronal image $(y=120)$, and a sagittal image $(x=$ 91) were displayed on an MRI template (ch2bet.nii.gz in MRIcron) in each patient. Yellow indicates voxels at $p<0.05$ (uncorrected, $>50$ voxels) and red indicates voxels at $p<0.01$ (uncorrected, $>50$ voxels) $\cdot\left[{ }^{11} \mathrm{C}\right] \mathrm{PBB} 3=2-\left([1 E, 3 E]-4-\left[6-\left(\left[{ }^{11} \mathrm{C}\right] \mathrm{meth}-\right.\right.\right.$ ylamino)pyridin-3-yl]buta-1,3-dienyl)benzo [d]thiazol-6-ol; CDR = Clinical Dementia Rating; $\mathrm{SOB}=$ sum of boxes. 
Figure 3 Increase of $\left[{ }^{11} \mathrm{C}\right] \mathrm{PBB} 3$ binding potential $\left(B P^{*}{ }_{\mathrm{ND}}\right)$ in 6 Kii amyotrophic lateral sclerosis (ALS)/parkinsonism dementia complex (PDC) patients compared with 13 old healthy controls (HCS)

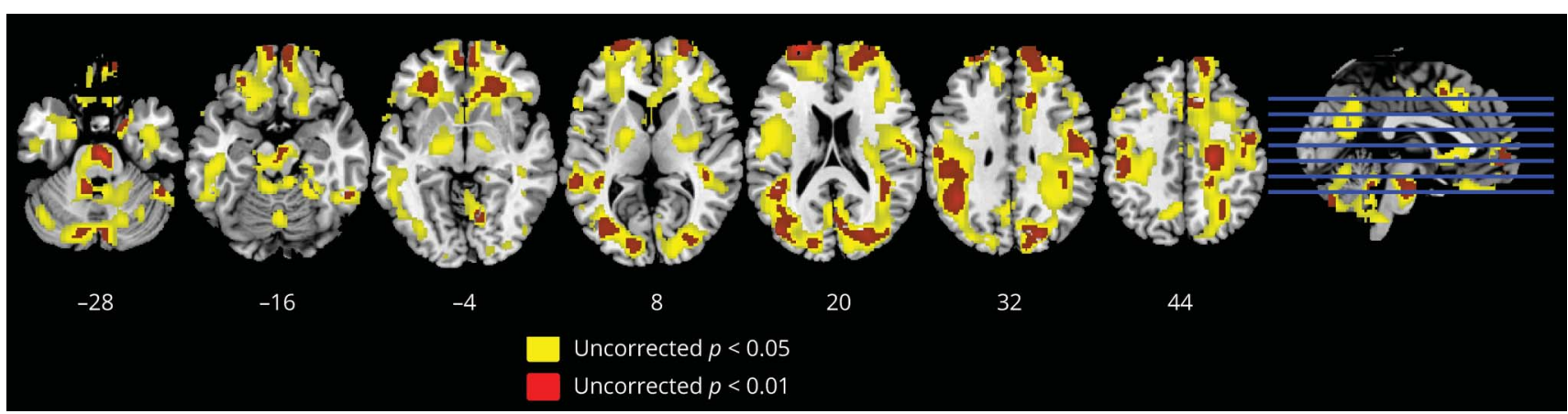

Seven trans-axial slices $(z=43,55,67,79,91,103,115 \mathrm{~mm})$ are displayed. Yellow indicates voxels at $p<0.05$ (uncorrected, $>50$ voxels) and red indicates voxels at $p<0.01$ (uncorrected, $>50$ voxels). $\left[{ }^{11} \mathrm{C}\right] \mathrm{PBB} 3=2-\left([1 E, 3 E]-4-\left[6-\left(\left[{ }^{11} \mathrm{C}\right]\right.\right.\right.$ methylamino)pyridin-3-yl]buta-1,3-dienyl)benzo[ $\left.d\right]$ thiazol-6-ol.

T1-weighted MRI of patient 1 was normal. T1-weighted MRI of patients 2-6 showed mild to moderate frontal, temporal, and parietal atrophy (figure 5).

\section{Kii ALS/PDC brain tissue staining}

Numerous NFTs and neuropil threads in the CA1 sector of the hippocampus were found to be positive for PBB3 and Gallyas-Braak silver staining in a histochemical analysis of the first series brain sections derived from 3 Kii ALS/PDC patients (CA1 of $65 \mathrm{M}$ is shown in figure 6A). However, the majority of NFTs in this area were negative for AT8, and accordingly were conceived to be extracellular ghost tangles. ${ }^{16,17}$ Moreover, tau aggregates in neuronal somas and putative axons were observed in the motor cortex as inclusions triply labeled with PBB3, AT8, and Gallyas-Braak silver staining (pathologies in the motor cortex of 63F shown in figure 6B). Axonal threads were triply stained in white matter adjacent to the cortex of 2 patients (77M and 63F; figure 6, C and D). Immunoreactive tau aggregates in neuronal somas and neurites were also noted in the striatum (staining in the posterior dorsal putamen of $63 \mathrm{~F}$ is shown in figure $6 \mathrm{E}$ ), but most of these tau aggregates was only modestly labeled with PBB3 and Gallyas-Braak silver staining, suggesting a relatively low packing density of these fibrillary assemblies. ${ }^{17}$

In the second series of specimens, PBB3-, AT8-, and GallyasBraak-positive tau aggregates were found as astrocytic plaquelike inclusions in gray matter (pathologies in the premotor cortex of $71 \mathrm{~F}$ is shown in figure $6 \mathrm{~F}$ ) and axonal threads in

Figure 4 Regional binding potential $\left(B P^{*}{ }_{N D}\right)$ of $\left[{ }^{11} \mathrm{C}\right] \mathrm{PBB} 3$ in 13 old healthy controls $(\mathrm{HCS})$ and 6 Kii amyotrophic lateral sclerosis (ALS)/parkinsonism dementia complex (PDC) patients

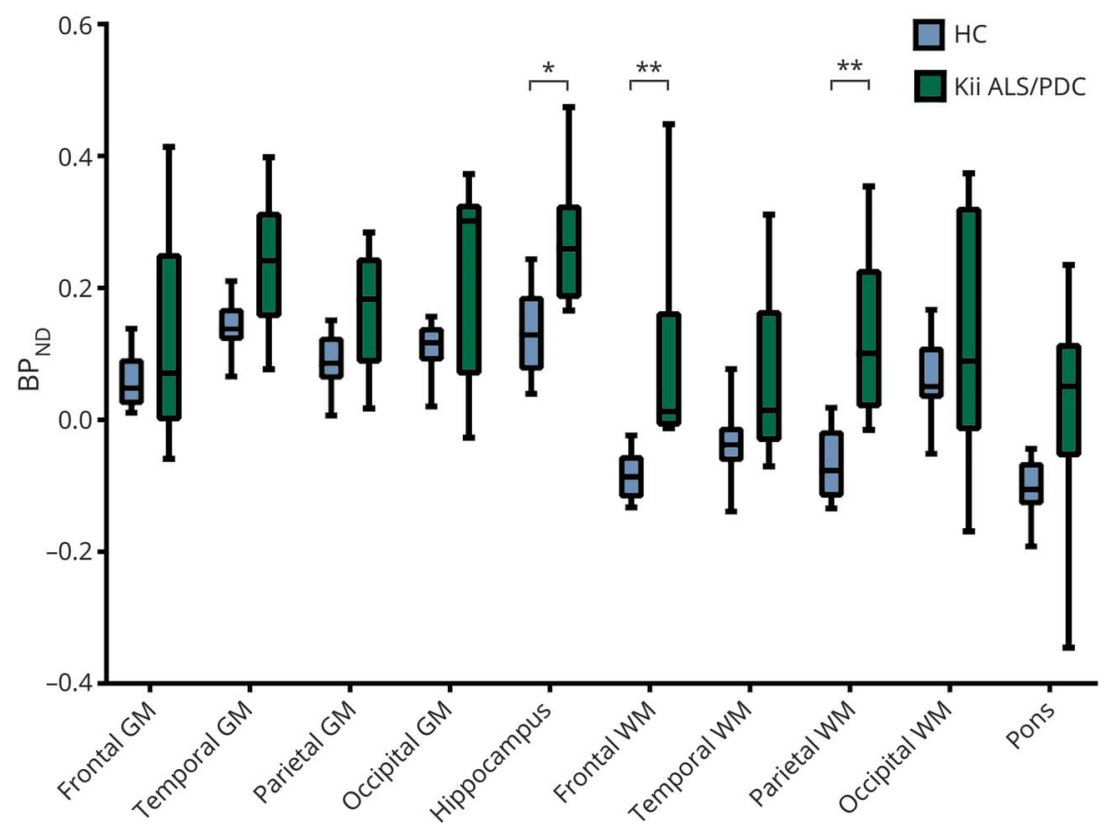

${ }^{*} p<0.05,{ }^{*} p<0.005$ by Holm-Sidak multiple comparisons test. Regions highlighted in bold type indicate those with differences in $B P{ }^{*} \mathrm{ND}$ between old HCs and Kii ALS/PDC patients. $\left[{ }^{11} \mathrm{C}\right] \mathrm{PBB} 3=2-([1 E, 3 E]-$ 4-[6-([ $\left[{ }^{11} \mathrm{C}\right]$ methylamino)pyridin-3-yl]buta-1,3-dienyl) benzo[d]thiazol-6-ol; GM = gray matter; WM = white matter. 


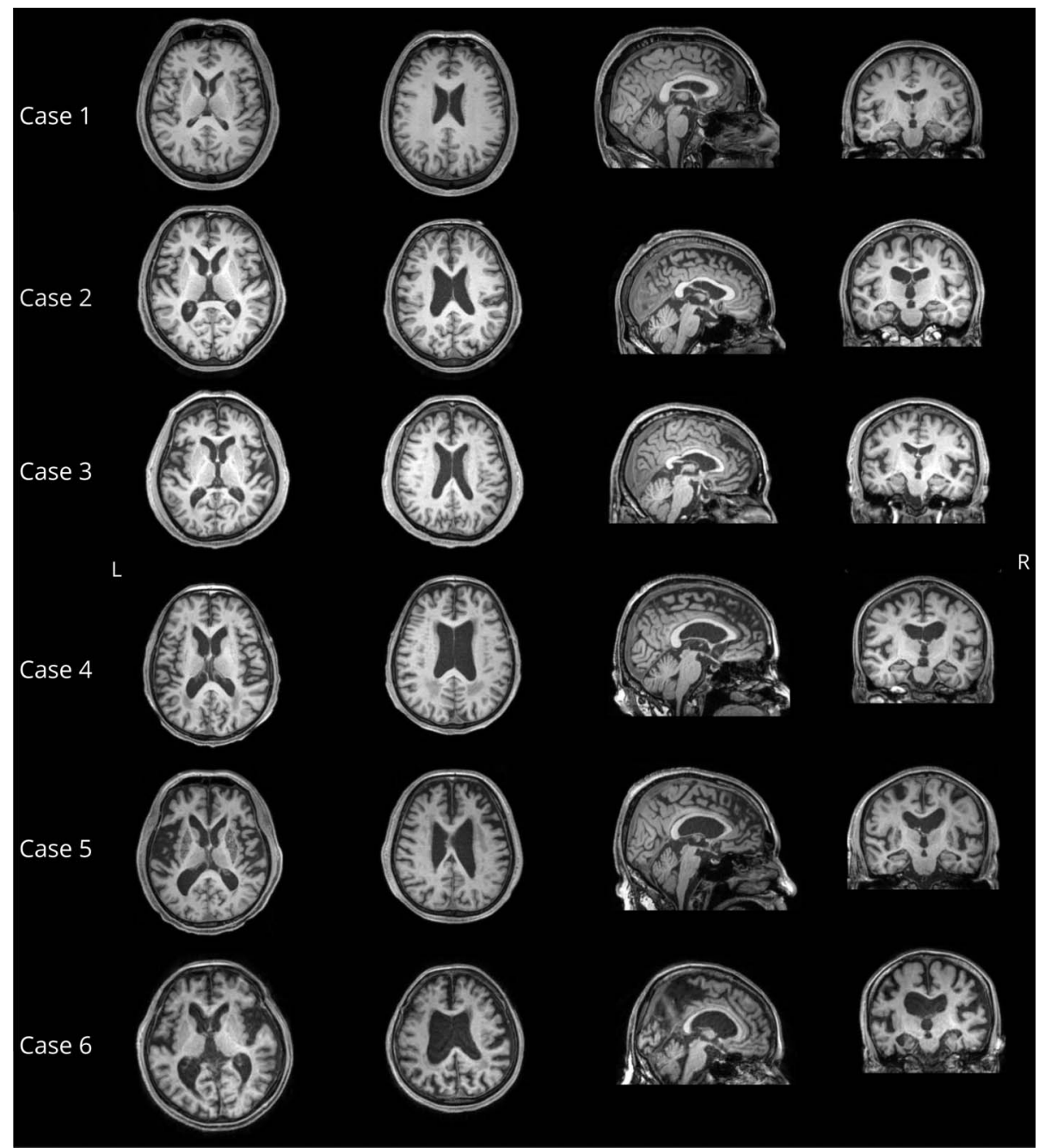

white matter (pathologies in subcortical white matter of $70 \mathrm{~F}$ is shown in figure 6G). Triple labeling of tau pathologies was also detected as lesions resembling oligodendrocytic coiled bodies beside axonal threads in white matter (staining in the posterior limb of the internal capsule of $71 \mathrm{~F}$ is shown in figure $6 \mathrm{H})$. These findings suggest that increased radioactivity retention in $\left[{ }^{11} \mathrm{C}\right] \mathrm{PBB} 3$ PET is attributable to radioligand binding to 4-repeat tau deposits in gray and white matter of a small subset of Kii ALS/PDC patients.

\section{Discussion}

$\left[{ }^{11} \mathrm{C}\right] \mathrm{PBB} 3 \mathrm{PET}$ demonstrated increased radioligand $B P^{*}{ }_{\mathrm{ND}}$, which is indicative of tau accumulation, in the brain of all 6 Kii ALS/PDC patients compared with 13 old HCs. Even in the asymptomatic patient (patient 1), $\left[{ }^{11} \mathrm{C}\right] \mathrm{PBB} 3$ binding was enhanced in gray matter of the cerebral cortex including the medial temporal lobe, subcortical white matter, and pontine base. Interestingly, a Kii ALS/PDC patient (patient 2), who exhibited prominent upper motor neuron signs, had increased tau accumulation in deep white matter and pontine base containing the corticospinal tract. There were more widespread regions with increased tau accumulation involving cortical and subcortical gray matter, white matter, and brainstem in Kii ALS/PDC patients with dementia (patients 3,5 , and 6). These findings suggest intimate associations between the topology of tau depositions and impairments of regional functions in the Kii ALS/PDC brains, implying that tau-induced neurotoxicity leads to deterioration of local neurons. This notion is supported by the present neuropathologic examination demonstrating abundant ghost tangles in the hippocampus of the patients.

There was a trend of increased tau accumulation in the brains of Kii ALS/PDC patients in association with CDR-SOB. However, patient 4 was an outlier with only modest increase of tau accumulation in the brain, and was also marginally positive for $A \beta$. The patient was born in the south part of the Kii peninsula, moved elsewhere at age 3, and developed symptoms 73 years later. ${ }^{18}$ Relatively low tau accumulation in the brain of this patient despite CDR-SOB 3 could be 
Figure 6 PBB3 fluorescent, AT8, and Gallyas-Braak (GB) staining in postmortem brains with Kii amyotrophic lateral sclerosis (ALS)/parkinsonism dementia complex (PDC) in the first (A-E) and second (F-H) series
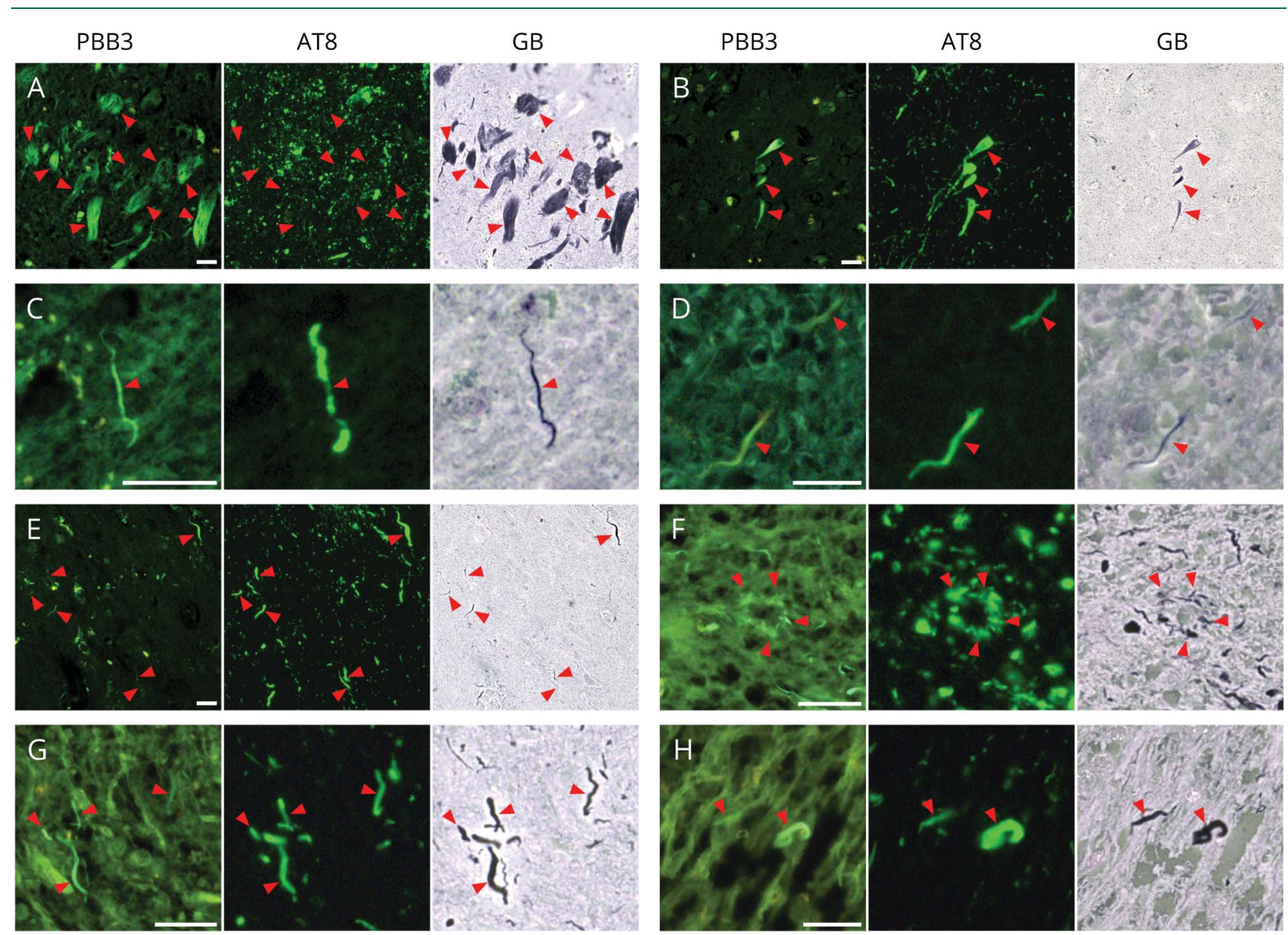

In the first series samples, numerous neurofibrillary tangles (NFTs) are positive for PBB3 and GB staining in the CA1 sector of the hippocampus, although the majority of NFTs in this area were negative for AT8 (A), in agreement with histopathologic features of extracellular ghost tangles. Tau aggregates in neuronal somas and putative axons were observed in the motor cortex as inclusions labeled with PBB3, AT8, and GB staining (B). Axonal threads in white matter adjacent to the cortex of 2 patients are labeled with PBB3, AT8, and GB staining (C, D). In the posterior dorsal putamen, there are tau aggregates in neuronal somas and neurites clearly labeled with AT8 but only partly labeled with PBB3 and GB staining (E), indicating the presence of tau deposits with relatively lower packing densities similar to pretangles. In the second series samples, astrocytic plaque-like inclusions are labeled with PBB3, AT8, and GB staining in the premotor cortex (F). Axonal threads are labeled with PBB3, AT8, and GB staining in white matter adjacent to the premotor cortex (G). Tau aggregates resembling oligodendrocytic coiled bodies beside axonal threads are labeled with PBB3, AT8, and GB staining in the posterior limb of the internal capsule (white matter) $(\mathrm{H})$. Red arrowheads indicate tau aggregates. $\left[{ }^{11} \mathrm{C}\right] \mathrm{PBB} 3=2-\left([1 \mathrm{E}, 3 \mathrm{E}]-4-\left[6-\left(\left[{ }^{11} \mathrm{C}\right]\right.\right.\right.$ methylamino $)$ pyridin-3-yl]buta-1,3-dienyl)benzo[ $\left.d\right]$ thiazol-6-ol

attributed to the shortest stay in the endemic area, and the longest incubation to develop the disease, and functional deficits in the brain of this patient may also result from accumulation of other pathogenetic proteins including $A \beta$.

The distribution of tau accumulation was rather scattered and variable among Kii ALS/PDC patients. A previous neuropathologic study showed that NFTs tended to appear discontinuously and nonsystematically in Kii ALS/PDC. ${ }^{3}$ This was in contrast to the neuropathologic features of $\mathrm{AD}$, in which NFTs are confined to gray matter, and spread systemically according to Braak histopathologic stages. ${ }^{7,8,19}$ VOI analysis of $\left[{ }^{11} \mathrm{C}\right] \mathrm{PBB} 3 \mathrm{PET}$ showed that tau aggregates were preferentially accumulated in the hippocampus and in frontal and parietal white matter in the 6 Kii ALS/PDC patients compared with the 13 old HCs, although voxel-wise SPM analysis did not reveal tau accumulation in the hippocampus of these patients. This discrepancy between VOI and voxelwise analyses might be explained by the diversity of the subregional distributions of tau aggregates in the hippocampus among the 6 patients.

Previous pathologic studies established that NFTs and neuropil threads are the main pathology of Kii ALS/PDC. ${ }^{1-3}$ In addition, tau-positive astrocytes are also found predominantly in subpial and perivascular areas and are focally seen in the white matter of all patients with Kii ALS/PDC. ${ }^{3}$ Our brain tissue staining study demonstrated that tau-positive threads in white matter are stained with PBB3 in all examined patients, although tau-positive astrocytes are stained with $\mathrm{PBB} 3$ only in a subpopulation of Kii ALS/PDC patients with corticobasal degeneration-like findings such as depositions resembling astrocytic plaques. The present PET study showed high $\left[{ }^{11} \mathrm{C}\right]$ PBB3 binding in white matter of the Kii ALS/PDC patients by 
VOI analysis. Voxel-based analysis of $\left[{ }^{11} \mathrm{C}\right] \mathrm{PBB} 3$ parametric images showed increased $\left[{ }^{11} \mathrm{C}\right] \mathrm{PBB} 3$ binding in not only subcortical white matter but also in deep white matter. Taken together, high $\left[{ }^{11} \mathrm{C}\right] \mathrm{PBB} 3$ binding in white matter should at least partly reflect tau pathologies in the white matter of Kii ALS/PDC patients, although it could also be attributed to the tau pathologies in cortical gray matter around the depth of a sulcus and gray-white boundary in the present image analysis, due to relatively low spatial resolution of PET data. Our preliminary histochemical assessments of brain sections indicated that the density of tau aggregates in gray matter in the vicinity of white matter is more than 10 -fold higher than the density of tau-positive threads in white matter. Hence, $\left[{ }^{11} \mathrm{C}\right]$ PBB3-PET signals in superficial white matter might be largely affected by tau deposits in deep gray matter. Another potential technical issue may be the possible binding of the radioligand to off-target components in white matter, as exemplified by cross-reactivity of THK-5,351 with monoamine oxidase $\mathrm{B}$ (MAO-B) expressed in activated astrocytes. ${ }^{20}$ However, our recent data have proven that PBB3 does not bind to MAO-B. ${ }^{21}$ Hence, PET imaging with $\left[{ }^{11} \mathrm{C}\right]$ $\mathrm{PBB} 3$ could offer an in vivo technology to capture $\mathrm{AD}$-like and CBD-like heterogeneous tau pathologies in Kii ALS/PDC.

The present results suggest that increased tau accumulation in gray matter of the frontal, temporal, and parietal lobes leads to cognitive deficits in Kii ALS/PDC, as assessed by MMSE. There was a correlation between tau accumulation in frontal gray matter and NPI scores, suggesting that tau accumulation also may contribute to neuropsychiatric symptoms such as apathy and irritability in Kii ALS/PDC patients.

Neuropathologic studies of Kii ALS/PDC patients showed that there were various types of phosphorylated $\alpha$-synucleinpositive lesions including neuronal cytoplasmic inclusions, dystrophic neurites, and glial cytoplasmic inclusions. ${ }^{3,22}$ Phosphorylated $\alpha$-synuclein was distributed mainly in the limbic system and brainstem of Kii ALS/PDC brains, ${ }^{3,22}$ while tau pathology is more prevalent than $\alpha$-synuclein pathology in most affected areas. ${ }^{22}$ Furthermore, our previous study demonstrated that PBB3 binding to $\alpha$-synuclein deposits is 10-50 times less than to tau deposits. ${ }^{23}$ Therefore, the increase of $\left[{ }^{11} \mathrm{C}\right] \mathrm{PBB} 3$ binding in the present study was mostly attributable to tau pathology in Kii ALS/PDC patients.

Only 2 (patients 3 and 6) of 5 Kii ALS/PDC patients with parkinsonism showed high radioligand binding in the striatum and midbrain including the substantia nigra in comparison with old HCs. Parkinsonism could result from neuronal loss in the substantia nigra induced by tau aggregates with or without $\alpha$-synuclein deposits in these Kii ALS/PDC patients, as Lewy body pathology is often found in the substantia nigra of Kii ALS/PDC brains. ${ }^{3}$ However, it should be noted that Lewy bodies, and Lewy neurites in dementia with Lewy bodies, are thought to be undetectable in vivo by $\left[{ }^{11} \mathrm{C}\right] \mathrm{PBB} 3$ PET according to our previous data. ${ }^{23}$
In addition to tau and $\alpha$-synuclein depositions, TDP-43 pathology is noted in the brain and spinal cord of patients with Kii ALS/PDC, similar to sporadic ALS. ${ }^{3}$ It has been reported that a patient with progressive supranuclear palsy phenotype associated with DCTN1 mutation showed increased $\left[{ }^{11} \mathrm{C}\right]$ PBB3 binding in basal ganglia and parietal lobe. ${ }^{24}$ Mutations of the DCTN1 gene have been mostly associated with ALS and Perry syndrome, and one of the neuropathologic features of Perry syndrome is the accumulation of ubiquitinated TDP43-positive neuronal inclusions, dystrophic neurites, glial cytoplasmic inclusions, and axonal spheroids. However, there have been no reports documenting the histopathology of progressive supranuclear palsy phenotype associated with DCTN1 mutation, and therefore the cross-reactivity of $\left[{ }^{11} \mathrm{C}\right]$ PBB3 with TDP-43 lesions remains to be determined.

There are a few technical considerations related to the quantification of radioligand binding in this study. SUVR, which is a target to reference the tissue radioactivity ratio at a near-equilibrium state of tracer kinetics, is usually used as an in vivo index of amyloid and tau accumulations. We calculated $B P^{*}{ }_{N D}$ of $\left[{ }^{11} \mathrm{C}\right] \mathrm{PBB} 3$ in the kinetic model instead of with SUVR, ${ }^{25}$ although this requires dynamic PET scans for several 10 -minute periods. The advantage of $B P^{*}{ }_{N D}$ over SUVR as an index of radioligand binding is that $B P^{*}{ }_{N D}$ is minimally affected by changes in cerebral blood flow. Moreover, the cerebellum is usually used as reference tissue, because this area lacks amyloid and tau pathologies in $\mathrm{AD}$. In contrast, a recent neuropathologic study showed that phosphorylated tau pathology of various types is present in the dentate nucleus and Purkinje and glial cells in the cerebellum of patients with Kii ALS/PDC. ${ }^{26}$ Therefore, we used gray matter voxels, which have a low likelihood of bearing tau pathology, as a reference instead of the cerebellum. ${ }^{27} B P^{*}{ }_{N D}$ measures in white matter might be biased due to a possible difference in nondisplaceable binding of PBB3 between gray matter and white matter. However, the current reference tissue determined in gray matter does not provoke a pronounced bias affecting interpretation of the results when comparing the patient and control groups, since the bias at issue should be constant among Kii ALS/PDC patients and old HCs and should not cause larger differences in white matter regions relative to gray matter regions. An alternative option to quantify specific binding of $\left[{ }^{11} \mathrm{C}\right] \mathrm{PBB} 3$ in white matter would be to generate reference tissue data by extracting voxels from white matter only on the basis of a white matter frequency histogram. However, the signal-to-noise ratio in white matter reference tissue may not be as high as the ratio in gray matter reference tissue, due to low nondisplaceable radioligand binding in white matter relative to gray matter. Accordingly, this would lead to decreased accuracy in the quantification of tau pathologies in white matter.

The limitation of this study is that only a small number of male Kii ALS/PDC patients were included in the PET imaging assays. Since the occurrence of Kii ALS/PDC is not sexspecific, PET studies with a large number of Kii ALS/PDC 
patients including female patients will be required to further validate the current findings. In addition, a pursuit of the relationships between neuroimaging and neuropathologic data in the same patients with Kii ALS/PDC will ascertain the utility of $\left[{ }^{11} \mathrm{C}\right] \mathrm{PBB} 3 \mathrm{PET}$ for assessing tau lesions in living patients.

$\left[{ }^{11} \mathrm{C}\right]$ PBB3 PET visualized the characteristic topography of tau pathology in Kii ALS/PDC, corresponding to clinical phenotypes of this disease.

\section{Acknowledgment}

The authors thank the staff of the Department of Radiopharmaceuticals Development and of the Clinical Neuroimaging Team, the Department of Functional Brain Imaging, National Institute of Radiological Sciences, National Institutes for Quantum and Radiological Science and Technology, Chiba, Japan, for support with radioligand synthesis and PET scans, and Dr. Shigeki Kuzuhara, Department of Nursing, Suzuka University of Medical Science, for support of all research projects with Kii ALS/PDC.

\section{Study funding}

This research was partly supported by grants-in-aid from the Research Committee of CNS Degenerative Diseases (H26Nanchi-Ippan-085, 2014-2016) and the Research Committee of Muro disease (Kii ALS/PDC) (21210301, 2009-2014) to Y. Kokubo from the Ministry of Health, Labor and Welfare (MHLW), Japan; Scientific Research (25305030) to Y. Kokubo from the Ministry of Education, Culture, Sports, Science and Technology (MEXT), Japan; the Research Consortium of Kii ALS/PDC (17ek0109139h0003, 2015-2017) to Y. Kokubo from the Japan Agency for Medical Research and Development (AMED); the Brain Mapping by Integrated Neurotechnologies for Disease Studies (Brain/ MINDS; 15653129) to T. Suhara and M. Higuchi from AMED; Research and Development Grants for Dementia (16768966) to M. Higuchi from AMED; Scientific Research on Innovative Areas to M. Higuchi ("Brain Environment" 23111009) and N. Sahara ("Brain Protein Aging" 26117001) from MEXT; the Mie Medical Fund and Japan Foundation for Neuroscience and Mental Health to Y. Kokubo, Japan; and the young scientists (A) (26713031) to H. Shimada from MEXT, Japan. H. Shimada was funded by the Mochida Memorial Foundation for Medical Pharmaceutical Research and the Life Science Foundation, Japan.

\section{Disclosure}

H. Shinotoh reports no disclosures relevant to the manuscript. H. Shimada holds a patent on compounds related to the present report (JP 5422782/EP 12884 742.3). Y. Kokubo, K. Tagai, F. Niwa, S. Kitamura, H. Endo, M. Ono, Y. Kimura, S. Hirano, M. Mimuro, M. Ichise, and N. Sahara report no disclosures relevant to the manuscript. M. Zhang holds a patent on compounds related to the present report (JP 5422782/EP 12884742.3 ). T. Suhara holds a patent on compounds related to the present report (JP 5422782/EP 12
884 742.3). M. Higuchi holds a patent on compounds related to the present report (JP 5422782/EP 12884742.3 ). Go to Neurology.org/ $\mathrm{N}$ for full disclosures.

\section{Appendix 1 Methods}

\section{Participants}

Five patients who were current or previous inhabitants of the southern part of the Kii Peninsula and met the clinical criteria for probable Kii ALS $/ \mathrm{PDC}^{9}$ were recruited at Mie University and affiliated hospitals, Okayama University, and Chiba University between 2014 and 2017. An asymptomatic participant from the southern part of the Kii Peninsula and with a dense family history of ALS/PDC also took part in this study. Thirteen healthy men ranging in age from 54 to 76 years participated as age- and sex-matched, healthy controls (old HCs). Eleven young healthy controls (5 men and 6 women, young HCs) ranging in age from 24 to 45 years took part in the study to optimize the PET data analysis. HCs were without any history of psychiatric and neurologic diseases, brain trauma, alcoholism, and drug abuse, and were cognitively and neurologically normal.

All patients and HCs were assessed by MMSE, FAB, CDR, and NPI, Unified UPDRS motor score at the time of the study.

\section{Standard protocol approvals, registrations, and patient consents}

This study was approved by the ethics committee of the National Institute of Radiologic Sciences, National Institutes for Quantum and Radiologic Science and Technology, and was registered in the University Medical Information Network Clinical Trials Registry (UMIN 000015453). Written informed consent was obtained from all participants and close family members of patients with Kii ALS/PDC and AD.

\section{Image acquisition}

All subjects underwent MRI, PET scans with $\left[{ }^{11} \mathrm{C}\right] \mathrm{PBB} 3$, and with $\left[{ }^{11} \mathrm{C}\right] \mathrm{PiB}$ in a day or 2 successive days at the National Institute of Radiologic Sciences, Chiba.

$\left[{ }^{11} \mathrm{C}\right] \mathrm{PBB} 3$ was radio-synthesized by reacting its desmethyl precursor (NARD Institute, Kobe, Japan) with $\left[{ }^{11} \mathrm{C}^{-\mathrm{CH}_{3} \mathrm{I} \text { in }}\right.$ the presence of potassium hydroxide, followed by deprotection with water as described previously. ${ }^{28}\left[{ }^{11} \mathrm{C}\right] \mathrm{PiB}$ was produced as documented elsewhere. ${ }^{29}$

PET images were acquired with a Siemens ECAT EXACT HR+ scanner (CTI PET Systems, Inc, Knoxville, TN) with an axial field of view (FOV) of $155 \mathrm{~mm}$, providing 63 contiguous 2.5-mm slices with 5.6-mm transaxial and 5.4-mm axial resolution. A transmission scan was performed for attenuation correction. Seventy-minute dynamic PET scans in 3-dimensional mode were performed after intravenous injection of $\left[{ }^{11} \mathrm{C}\right] \mathrm{PBB} 3$ (injected dose, $450 \pm 80 \mathrm{MBq}$; molar activity at the time of injection, $82 \pm 36 \mathrm{GBq} / \mu \mathrm{mol}$ ), and 
$\left[{ }^{11} \mathrm{C}\right] \mathrm{PiB}$ (injected dose, $436 \pm 73 \mathrm{MBq}$; molar activity at the time of injection, $74 \pm 34 \mathrm{GBq} / \mu \mathrm{mol})$. Dynamic emission scans consisted of $6 \times 10$ seconds, $3 \times 20$ seconds, $6 \times 1$ minute, $4 \times 3$ minutes and $10 \times 5$ minutes frames in $\left[{ }^{11} \mathrm{C}\right]$ PBB3- and $\left[{ }^{11} \mathrm{C}\right] \mathrm{PiB}-\mathrm{PET}$. One of the Kii ALS/PDC patients (case 6) was unable to lie still for 70 minutes, so the scans were performed for 50 minutes after $\left[{ }^{11} \mathrm{C}\right] \mathrm{PBB} 3$ injection, and from 50 to 70 minutes after $\left[{ }^{11} \mathrm{C}\right] \mathrm{PiB}$ injection.

MR images were obtained with 3.0T Signa HDx (GE Healthcare, WI) in $22 \mathrm{HCs}$, and with 3.0T MAGNETOM Verio (Siemens Healthcare, Erlangen, Germany) in 6 Kii ALS/PDC patients and 2 HCs. T1-weighted images were taken for co-registration and segmentation of PET images (Signa HDxt: axial orientate as 1-mm thick sections, TE 2.85 ms, TR $7.00 \mathrm{~ms}$, flip angle 8.0 degrees, TI $900 \mathrm{~ms}$, FOV $260 \mathrm{~mm}$, matrix size $256 \times 256 \times 166$; MAGNETOM Verio: sagittal orientate as $1-\mathrm{mm}$ thick sections, TE $1.95 \mathrm{~ms}$, TR 2,300 ms, flip angle 9.0 degrees, TI 900 ms, FOV 250 mm, matrix size $512 \times 512 \times 176$ ).

\section{Image analysis}

All PET images were reconstructed with a filtered back projection method and corrected for attenuation and scatter. A quantitative estimate of $\left[{ }^{11} \mathrm{C}\right] \mathrm{PBB} 3$ binding, $B P^{*}{ }_{\mathrm{ND}}$, was calculated on a voxel basis using a multilinear reference tissue model $\left(\mathrm{MRTM}_{\mathrm{O}}\right)$ on the 50-minute sequential PET scan data after motion correction to generate parametric PET images. ${ }^{25}$ Since tau pathology might exist in the cerebellum of patients with Kii ALS/PDC, ${ }^{26}$ the cerebellum was not used as reference tissue. Instead, an optimized reference tissue method was used to minimize inclusion of tau-positive areas in a reference tissue as previously described. ${ }^{27}$ Parametric $B P^{*}{ }_{\mathrm{ND}}$ images were initially generated using reference tissue manually defined on the cerebellar cortex. Then a frequency histogram of $B P^{*}{ }_{\text {ND }}$ values was obtained from these parametric images, and cortical gray matter voxels in a certain range of the histogram with a low likelihood of having $\left[{ }^{11} \mathrm{C}\right] \mathrm{PBB} 3$ specific binding were extracted as optimized reference tissue voxels. In the present study, the range of the $B P^{*}{ }_{N D}$ histogram for reference tissue was set at 0.36 and the lower limit of this range was set at -2 SD to threshold out noisy voxels data available from Dryad (figure e-1a, doi.org/10.5061/dryad.241d1fs). The $B P^{*}{ }_{N D}$ range of 0.36 was determined as the mean fullwidth at half-maximum of $B P^{*}{ }_{N D}$ histograms in 11 young $\mathrm{HCs}$ who were supposedly devoid of tau pathology. Reference voxels were extracted by intersecting voxels with $B P^{*}{ }_{N D}$ values above mean -2 SD for a range of 0.36 and cortical and cerebellar cortical gray matter on MRI in each participant data available from Dryad (figure e-1b). Time-radioactivity curves in all extracted reference voxels were averaged, and a $B P^{*}{ }_{\mathrm{ND}}$ parametric image was generated using $\mathrm{MRTM}_{\mathrm{O}}$ and this averaged reference curve.

An automated analysis of VOIs was performed using the PNEURO module in the PMOD software (Version. 3.8,
PMOD Technologies, Zurich, Switzerland). This software allows the placement of standard VOIs on individual native PET space using individual T1-weighted MR images. Partial volume correction was not performed. VOIs were defined in the following regions: frontal, temporal, parietal, and occipital gray matters, hippocampus, white matter, and pons using the Automated Anatomical Labeling Merged atlas and individual segmented MRI data. Cerebral white matter was divided into frontal, temporal, parietal and occipital white matters using VOIs in the WFU-Pickatlas (fmri.wfubmc.edu/software/ PickAtlas). For voxel-based analysis, $\left[{ }^{11} \mathrm{C}\right] \mathrm{PBB} 3 \mathrm{BP}{ }_{\mathrm{ND}}^{*}$ images were normalized to the Montreal Neurologic Institute stereotactic space, and smoothed using a 8-mm full-width at half-maximum isotropic Gaussian kernel using SPM12 running on MATLAB R2015b (Mathworks Inc, Sherborn, MA). $\left[{ }^{11} \mathrm{C}\right]$ PBB3 $B P^{*}{ }_{\mathrm{ND}}$ images of each Kii ALS/PDC patient were compared with those of 13 old HCs in a voxel-by-voxel manner by 2 -sample $t$ test in a single-case SPM analysis. Group comparisons by 2-sample $t$ tests in SPM12 were also performed between the 6 Kii ALS/PDC patients and 13 old HCs. The results were displayed on the MRI template in MRIcron (people.cas.sc.edu/rorden/mricron/index.html).

Parametric $\left[{ }^{11} \mathrm{C}\right] \mathrm{PiB}$ images for amyloid $\beta$ were generated by voxel-based calculation of standardized uptake value ratio (SUVR) at 50-70 minutes between the target voxel and cerebellar cortex VOI. The whole cerebral cortical SUVR was calculated on spatially normalized parametric $\left[{ }^{11} \mathrm{C}\right] \mathrm{PiB}$ images. $\left[{ }^{11} \mathrm{C}\right] \mathrm{PiB}$ retention was assessed by visual inspection of SUVR images, and classified as $\mathrm{PiB}(+)$ when $\left[{ }^{11} \mathrm{C}\right] \mathrm{PiB}$ uptake in gray matter of more than one gyrus exceeded those in white matter, and $\mathrm{PiB}(-)$ when $\left[{ }^{11} \mathrm{C}\right] \mathrm{PiB}$ uptake in gray matter was equal to or lower than those in white matter.

\section{Statistical analysis}

The demographic parameters of the participants were statistically examined by 2 -sample $t$ test. Multiple $t$ tests followed by Holm-Sidak multiple comparisons test were performed to assess differences in regional $\left[{ }^{11} \mathrm{C}\right] \mathrm{PBB} 3 \mathrm{BP}_{\mathrm{ND}}^{*}$ between the 6 Kii ALS/PDC patients and the 13 old HCs in a VOI analysis. Spearman's correlational analysis was performed between regional $\left[{ }^{11} \mathrm{C}\right] \mathrm{PBB} 3 \mathrm{BP}^{*}{ }_{\mathrm{ND}}$ and clinical and cognitive scores in Kii ALS/PDC patients. Corrections for multiple comparison were not performed in the correlational analysis. A $p$ value $<0.05$ was considered significant. These analyses were performed using GraphPad Prism 7 software (GraphPad, San Diego, CA). Voxel-by voxel 2-sample $t$ tests of $\left[{ }^{11} \mathrm{C}\right]$ PBB3 $B P_{\text {ND }}^{*}$ images were performed at liberal thresholds (height threshold, $p=0.05$ and $p=0.01$, uncorrected; extent threshold $=50$ voxels) in SPM 12 because of the exploratory nature of this study.

\section{Kii ALS/PDC brain tissue staining}

PBB3 staining of brain tissues was examined in another cohort of Kii ALS/PDC patients. Post-mortem human brain tissues 
were obtained from autopsies of 3 patients with Kii ALS-PDC ("first series" samples, corresponding to cases 1 [63F; age/ sex ], $2[65 \mathrm{M}], 8[77 \mathrm{M}]$ in a previous report ${ }^{3}$ ) carried out at the Department of Oncologic Pathology, Mie University School of Medicine, and examined at the Department of Neuropathology of Aichi Medical University. Tissues were fixed in $10 \%$ neutral buffered formalin followed by embedding in paraffin blocks. We performed PBB3 staining, immunostaining, and Gallyas-Braak silver staining of brain tissue samples at the National Institute of Radiologic Sciences, Chiba. For fluorescence labelling with PBB3, 4.5- $\mu \mathrm{m}$ thick deparaffinized sections were incubated in $50 \%$ ethanol containing $0.001 \%$ PBB3 at room temperature for 30 minutes. The samples were rinsed with 50\% ethanol for 5 minutes, dipped into distilled water twice for 3 minutes each, and mounted in non-fluorescent mounting media (VECTASHIELD; Vector Laboratories, Burlingame, CA). Fluorescence images were captured using a DM4000 microscope (Leica, Wetzler, Germany) equipped with a custom filter cube for PBB3 (excitation band-pass at 391-437 $\mathrm{nm}$ and suppression low-pass with $458 \mathrm{~nm}$ cut-off). ${ }^{7}$ Following fluorescence microscopy, all sections labelled with PBB3 were autoclaved for antigen retrieval and immunostained with anti-tau monoclonal antibody against tau phosphorylated at Ser202 and Thr205 (AT8: Thermo Fisher Scientific, Waltham, MA). Immunolabelling was then examined using DM4000. Finally, the tested samples were used for Gallyas-Braak silver staining with Nuclear Fast Red (Sigma-Aldrich, Burlington, MA) counter-staining after pretreatment with $0.25 \%$ $\mathrm{KMnO}_{4}$ followed by $2 \%$ oxalic acid.

Since our pilot neuropathologic study at the Department of Neuropathology of Aichi Medical University indicated depositions of 4-repeat tau aggregates in glial cells along with $\mathrm{AD}$ like neuronal tau inclusions composed of all 6 tau isoforms in 2 out of more than 20 consecutive autopsy cases with Kii ALS/PDC, we conducted histochemical and immunohistochemical staining of brain slices derived from these cases ("second series" samples, corresponding to cases $11[70 \mathrm{~F}]$ and $12[71 \mathrm{~F}]$ in a previous report $\left.{ }^{3}\right]$ according to the abovementioned procedures, in order to examine the reactivity of PBB3 with these glial tau pathologies.

\section{Data sharing statement}

Anonymized data in the article may be shared upon reasonable request from any qualified investigator.

Appendix 2 Author contributions

\begin{tabular}{|c|c|c|c|}
\hline Name & Location & Role & Contribution \\
\hline $\begin{array}{l}\text { Hitoshi Shinotoh, MD, } \\
\text { PhD }\end{array}$ & NIRS, Chiba & Author & $\begin{array}{l}\text { Study concept and design, data acquisition and analysis, writing the } \\
\text { manuscript }\end{array}$ \\
\hline $\begin{array}{l}\text { Hitoshi Shimada, MD, } \\
\text { PhD }\end{array}$ & NIRS, Chiba & Author & $\begin{array}{l}\text { Study concept and design, data acquisition and analysis, writing the } \\
\text { manuscript }\end{array}$ \\
\hline $\begin{array}{l}\text { Yasumasa Kokubo, MD, } \\
\text { PhD }\end{array}$ & Mie University & Author & Study concept and design, participant recruitment \\
\hline Kenji Tagai, MD & NIRS, Chiba & Author & Data acquisition and analysis \\
\hline Fumitoshi Niwa, MD, PhD & $\begin{array}{l}\text { Kyoto Prefectural University of } \\
\text { Medicine }\end{array}$ & Author & Data acquisition and analysis \\
\hline $\begin{array}{l}\text { Soichiro Kitamura, MD, } \\
\text { PhD }\end{array}$ & Nara Medical University & Author & Data acquisition and analysis \\
\hline Hironobu Endo, MD, PhD & Kobe University, Hyogo & Author & Data acquisition and analysis \\
\hline Maiko Ono, PhD & NIRS, Chiba & Author & Data acquisition and analysis of postmortem brain tissues \\
\hline $\begin{array}{l}\text { Yasuyuki Kimura, MD, } \\
\text { PhD }\end{array}$ & NCGG, Aichi & Author & Data acquisition and analysis, writing the manuscript \\
\hline Shigeki Hirano, MD, PhD & Chiba University & Author & Data acquisition and analysis \\
\hline Maya Mimuro, MD, PhD & Aichi Medical University & Author & Data acquisition and analysis of postmortem brain tissues \\
\hline Masanori Ichise, MD, PhD & NIRS, Chiba & Author & Scientific advice and data analysis \\
\hline Naruhiko Sahara, PhD & NIRS, Chiba & Author & Analysis of postmortem brain tissues \\
\hline Ming-Rong Zhang, PhD & NIRS, Chiba & Author & Radioligand synthesis and data analysis \\
\hline Tetsuya Suhara, MD, PhD & NIRS, Chiba & Author & Study concept and design \\
\hline Makoto Higuchi, MD, PhD & NIRS, Chiba & Author & $\begin{array}{l}\text { Study concept and design, data acquisition and analysis, writing the } \\
\text { manuscript }\end{array}$ \\
\hline
\end{tabular}




\begin{tabular}{|c|c|c|c|}
\hline Name & Location & Role & Contribution \\
\hline Ryogen Sasaki, MD, PhD & National Mie Hospital, Mie & $\begin{array}{l}\text { Site } \\
\text { Investigator }\end{array}$ & Participant recruitment \\
\hline $\begin{array}{l}\text { Satoru Morimoto, MD, } \\
\text { PhD }\end{array}$ & $\begin{array}{l}\text { Tokyo Metropolitan Geriatric Hospital and Institute of Gerontology, } \\
\text { Tokyo }\end{array}$ & $\begin{array}{l}\text { Site } \\
\text { Investigator }\end{array}$ & Participant recruitment \\
\hline Toru Yamashita, MD, PhD & Okayama University & $\begin{array}{l}\text { Site } \\
\text { Investigator }\end{array}$ & Participant recruitment \\
\hline Ikuko Aiba, MD, PhD & Higashi-Nagoya National Hospital & $\begin{array}{l}\text { Site } \\
\text { Investigator }\end{array}$ & Participant recruitment \\
\hline $\begin{array}{l}\text { Satoshi Watanabe, MD, } \\
\text { PhD }\end{array}$ & Mie University, Mie & $\begin{array}{l}\text { Site } \\
\text { Investigator }\end{array}$ & $\begin{array}{l}\text { Collecting brain tissues of Kii ALS/ } \\
\text { PDC }\end{array}$ \\
\hline Mari Yoshida, MD, PhD & Aichi Medical University & $\begin{array}{l}\text { Site } \\
\text { Investigator }\end{array}$ & $\begin{array}{l}\text { Collecting brain tissues of Kii ALS/ } \\
\text { PDC }\end{array}$ \\
\hline $\begin{array}{l}\text { Satoshi Kuwabara, MD, } \\
\text { PhD }\end{array}$ & Chiba University, Chiba & $\begin{array}{l}\text { Site } \\
\text { Investigator }\end{array}$ & Participant recruitment \\
\hline
\end{tabular}

Abbreviations: NCGG = National Center for Geriatrics and Gerontology; NIRS = National Institute of Radiological Sciences, National Institutes for Quantum and Radiological Science and Technology.

\section{Publication history}

Received by Neurology May 15, 2018. Accepted in final form September 10, 2018.

\section{References}

1. Kuzuhara S, Kokubo Y, Sasaki R, et al. Familial amyotrophic lateral sclerosis and parkinsonism-dementia complex of the Kii peninsula of Japan: clinical and neuropathological study and tau analysis. Ann Neurol 2001;49:501-511.

2. Mimuro M, Kokubo Y, Kuzuhara S. Similar topographical distribution of neurofibrillary tangles in amyotrophic lateral sclerosis and parkinsonism-dementia complex in people living in the Kii peninsula of Japan suggest a single tauopathy. Acta Neuropathol 2007:113;653-658.

3. Mimuro M, Yoshida M, Kuzuhara S, Kokubo Y. Amyotrophic lateral sclerosis and parkinsonism-dementia complex of the Hohara focus of the Kii Peninsula: a multiple proteinopathy? Neuropathology 2018;38:98-107.

4. Itoh $\mathrm{N}$, Ishiguro $\mathrm{K}$, Arai $\mathrm{H}$, et al. Biochemical and ultrastructural study of neurofibrillary tangles in amyotrophic lateral sclerosis/parkinsonism-dementia complex in the Kii peninsula of Japan. J Neuropathol Exp Neurol 2003;62:791-798.

5. Buée-Scherrer V, Buée L, Hof PR, et al. Neurofibrillary degeneration in amyotrophic lateral sclerosis/parkinsonism-dementia complex of Guam: immunochemical characterization of tau proteins. Am J Pathol 1995;146:924-932.

6. Hata $\mathrm{Y}, \mathrm{Ma} \mathrm{N}$, Yoneda $\mathrm{M}$, et al. Nitrative stress and tau accumulation in amyotrophic lateral sclerosis/parkinsonism-dementia complex (ALS/PDC) in the Kii peninsula, Japan. Front Neurosci 2018;11:751

7. Maruyama M, Shimada H, Suhara T, et al. Imaging of tau pathology in a tauopathy mouse model and in Alzheimer patients compared to normal controls. Neuron 2013; 79:1094-1108

8. Shimada H, Kitamura S, Shinotoh $\mathrm{H}$, et al. Association between $\mathrm{A} \beta$ and tau accumulations and their influence on clinical features in aging and Alzheimer's disease spectrum brains: a $\left[{ }^{11} \mathrm{C}\right] \mathrm{PBB} 3-\mathrm{PET}$ study. Alzheimers Dement (Amst) 2016;6:11-20.

9. Kokubo Y. Diagnostic criteria for amyotrophic lateral sclerosis/parkinsonismdementia complex in the Kii peninsula, Japan [in Japanese with English abstract]. Brain Nerve 2015;67:961-966.

10. Folstein MF, Robins LN, Helzer JE. The mini-mental state examination. Arch Gen Psychiatry 1983;40:812.

11. Dubois B, Slachevsky A, Litvan I, Pillon B. The FAB: a frontal assessment battery at bedside. Neurology 2000;55:1621-1626.

12. Morris JC. The Clinical Dementia Rating (CDR): current version and scoring rules. Neurology 1993;43:2412-2414.

13. Cummings JL, Mega M, Gray K, et al. The Neuropsychiatric Inventory: comprehensive assessment of psychopathology in dementia. Neurology 1994;44: $2308-2314$.
14. Fahn S, Elton R; Members of the UPDRS Development Committee. The Unified Parkinson's Disease Rating Scale. In: Fahn S, Marsden CD, Calne D, Goldstein M, eds. Recent Developments in Parkinson's Disease. Florham Park: MacMillan HealthCare Information; 1987:153-163.

15. Mori S, Wakana S, Nagae-Poetscher LM, van Zijl PCM. MRI Atlas of Human White Matter. Amsterdam: Elsevier; 2005.

16. Dickson DW, Ksiezak-Reding H, Liu WK, Davies P, Crowe A, Yen SH. Immunocytochemistry of neurofibrillary tangles with antibodies to subregions of tau protein: identification of hidden and cleaved tau epitopes and a new phosphorylation site. Acta Neuropathol 1992;84:596-605.

17. Ono M, Sahara N, Kumata K, et al. Distinct binding of two PET ligands, PBB3 and AV1451, to tau fibril strains in neurodegenerative tauopathies. Brain 2017;140:764-780.

18. Tsunoda K, Yamashita $\mathrm{T}$, Shimada H, et al. A migration case of Kii amyotrophic lateral sclerosis/parkinsonism dementia complex with the shortest stay in the endemic area and the longest incubation to develop the disease. J Clin Neurosci 2017;46:64-67.

19. Schwarz AJ, Yu P, Miller BB, et al. Regional profiles of the candidate tau PET ligand ${ }^{18} \mathrm{~F}-\mathrm{AV}-1451$ recapitulate key features of Braak histopathological stages. Brain 2016; 139:1539-1550.

20. Ng KP, Pascoal TA, Mathotaarachchi S et al. Monoamine oxidase B inhibitor, selegiline, reduces ${ }^{18} \mathrm{~F}$-THK5351 uptake in the human brain. Alzheimers Res Ther 2017; 9:25.

21. Ni R, Ji B, Ono M, et al. Comparative in-vitro and in-vivo quantifications of pathological tau deposits and their association with neurodegeneration in tauopathy mouse models. J Nucl Med 2018;59:960-966.

22. Kokubo Y, Taniguchi A, Hasegawa M, et al. $\alpha$-Synuclein pathology in the amyotrophic lateral sclerosis/parkinsonism dementia complex in the Kii peninsula, Japan. J Neuropathol Exp Neurol 2012;71:625-630.

23. Koga S, Ono M, Sahara N, Higuchi M, Dickson DW. Fluorescence and autoradiographic evaluation of tau positron emission tomography ligand PBB3 to $\alpha$-synuclein pathology. Mov Disord 2017;32:884-892.

24. Perez-Soriano A, Arena JE, Dinelle K, et al. PBB3 imaging in parkinsonian disorders: evidence for binding to tau and other proteins. Mov Disord 2017;32: $1016-1024$.

25. Kimura $\mathrm{Y}$, Ichise $\mathrm{M}$, Ito $\mathrm{H}$, et al. PET quantification of tau pathology in human brain with ${ }^{11}$ C-PBB3. J Nucl Med 2015;56:1359-1365.

26. Morimoto S, Hatsuta H, Kokubo Y, et al. Unusual tau pathology of the cerebellum in patients with amyotrophic lateral sclerosis/parkinsonism-dementia complex from the Kii peninsula Japan. Brain Pathol 2018;28:287-291.

27. Kimura $Y$, Endo $\mathrm{H}$, Ichise, et al. A new method to quantify tau pathologies with $\left[{ }^{11} \mathrm{C}\right]$ PBB3 PET using reference tissue voxels extracted from brain cortical gray matter EJNMMI Res 2016;6:24

28. Hashimoto H, Kawamura K, Igarashi N, et al. Radiosynthesis, photoisomerization, biodistribution, and metabolite analysis of $11 \mathrm{C}-\mathrm{PBB} 3$ as a clinically useful PET probe for imaging of tau pathology. J Nucl Med 2014;55:1532-1538.

29. Maeda J, Ji B, Irie T, et al. Longitudinal, quantitative assessment of amyloid, neuroinflammation, and anti-amyloid treatment in a living mouse model of Alzheimer's disease enabled by positron emission tomography. J Neurosci 2007;27:10957-10968. 


\section{Neurology}

\section{Tau imaging detects distinctive distribution of tau pathology in ALS/PDC on the Kii Peninsula}

Hitoshi Shinotoh, Hitoshi Shimada, Yasumasa Kokubo, et al.

Neurology 2019;92;e136-e147 Published Online before print December 7, 2018

DOI 10.1212/WNL.0000000000006736

This information is current as of December 7, 2018

\section{Updated Information \&} Services

References

Citations

Subspecialty Collections

Permissions \& Licensing

Reprints including high resolution figures, can be found at: http://n.neurology.org/content/92/2/e136.full

This article cites 27 articles, 7 of which you can access for free at: http://n.neurology.org/content/92/2/e136.full\#ref-list-1

This article has been cited by 1 HighWire-hosted articles: http://n.neurology.org/content/92/2/e136.full\#\#otherarticles

This article, along with others on similar topics, appears in the following collection(s):

All Cognitive Disorders/Dementia

http://n.neurology.org/cgi/collection/all_cognitive_disorders_dementia Alzheimer's disease

http://n.neurology.org/cgi/collection/alzheimers_disease

Amyotrophic lateral sclerosis

http://n.neurology.org/cgi/collection/amyotrophic_lateral_sclerosis_ Parkinson's disease/Parkinsonism

http://n.neurology.org/cgi/collection/parkinsons_disease_parkinsonism PET

http://n.neurology.org/cgi/collection/pet

Information about reproducing this article in parts (figures,tables) or in its entirety can be found online at:

http://www.neurology.org/about/about_the_journal\#permissions

Information about ordering reprints can be found online:

http://n.neurology.org/subscribers/advertise

Neurology ${ }^{\circledR}$ is the official journal of the American Academy of Neurology. Published continuously since 1951, it is now a weekly with 48 issues per year. Copyright Copyright ( 2018 The Author(s). Published by Wolters Kluwer Health, Inc. on behalf of the American Academy of Neurology.. All rights reserved. Print ISSN: 0028-3878. Online ISSN: 1526-632X.

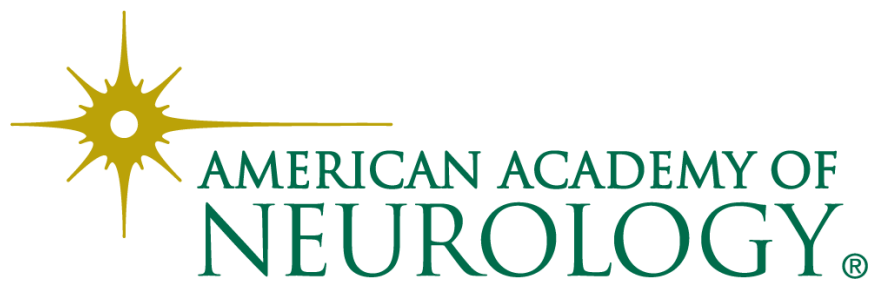

